\title{
ACUTE NON-SPECIFIC PERICARDITIS
}

\author{
BY \\ W. G. A. SWAN \\ From the Regional Cardiovascular Department, Newcastle General Hospital
}

Received January 29, 1960

The general features of acute non-specific (benign) pericarditis are now well known from the large number of cases reported from the United States (Barnes and Burchell, 1942; Carmichael et al., 1951; Scherl, 1956; Chapman and Overholt, 1957) and Scandinavia (Krook, 1954). Accounts from this country are limited to smaller numbers of patients (Davies, 1952; Bower et al., 1953; Will and Fleming, 1958). A clear pattern emerges from these reports and it is not proposed to describe the syndrome in elaborate detail but rather to emphasize certain unusual features and difficulties that have occurred in the present series of fourteen patients.

The clinical picture of the ordinary uncomplicated case of acute non-specific pericarditis (ANSP) is usually that of a young man who complains of severe retrosternal pain which is made worse by movement and breathing. The temperature is raised and pericardial friction is present. The electrocardiogram shows uniform elevation of the S-T period in most leads, without abnormal $Q$ waves, followed in a few days by lowering of the $T$ waves as the $S-T$ period returns to the isoelectric level. $\mathrm{T}$ wave inversion follows and the tracing then returns to normal (Fig. 1 and 2). Radiological enlargement of the heart shadow due to pericardial effusion is commonly seen and there may be pleural effusion (Fig. 3). Increase of jugular venous pressure may occur. After a period of days or weeks all the abnormalities disappear and full recovery takes place. An upper respiratory infection often precedes or accompanies the onset of the illness.

In the present series five cases followed this course and call for no special comment, but others showed unusual and sometimes puzzling features which will be mentioned in more. detail. All the patients were men and their ages ranged from 19 to 75 years. One patient died (see Table).

Pericardial friction is not invariably heard. It was absent in three patients and in another it was heard on one day only (Case 2). The occurrence of ANSP without friction has been previously noted; there were $13(26 \%)$ in Carmichael's (1951) 50 patients and $11(37 \%)$ in Scherl's (1956) 30 patients. No friction was heard in the fatal case of Pomerance et al. (1952).

The number of patients who had repeated attacks, sometimes over long periods, is a striking feature of this series. In Case 1 there was a history of 17 attacks of retrosternal pain during 16 years: in two of these a friction rub was heard by doctors and in most of the others by the patient and his wife. In Case 5 there were 8 attacks of pain, 6 of which were observed, during 5 years: friction was heard in only one of the attacks. Another patient, Case 11, had 5 attacks of pain during 8 months but no rub was ever heard. Three attacks occurred in two patients, Cases 3 and 12, and 2 in one, Case 4. Recurrences have been frequently observed and were noted by Carmichael et al. (1951) in probably $9(18 \%)$ of their patients. Krook (1954) records 13 patients with relapses out of 24 and one had 8 attacks in 10 years. Scherl (1956) notes relapses in $11(36 \%)$ of his cases. Tomlin et al. (1952) describes a woman who had 19 attacks of chest pain between the ages of 6 and 27 years, in two of which she was examined: $T$ wave changes only were found in the first attack but in the second friction was heard. They quote seven other cases with from 2 to 9 recurrences. Katz and Jackson (1957) describe a patient with 3 attacks in 8 years. 


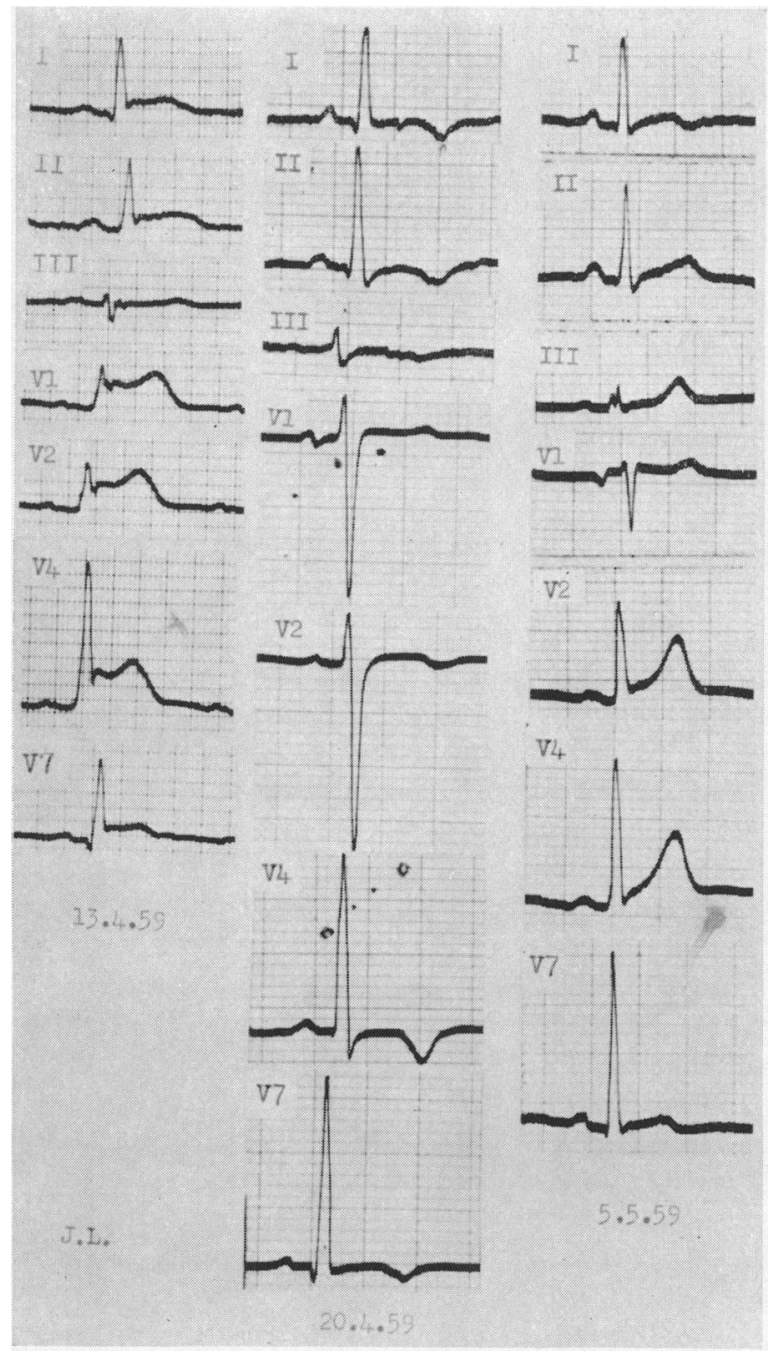

Fig. 1.-Electrocardiogram from Case 13 on $3 \mathrm{rd}, 10 \mathrm{th}$, and 25 th day of illness.

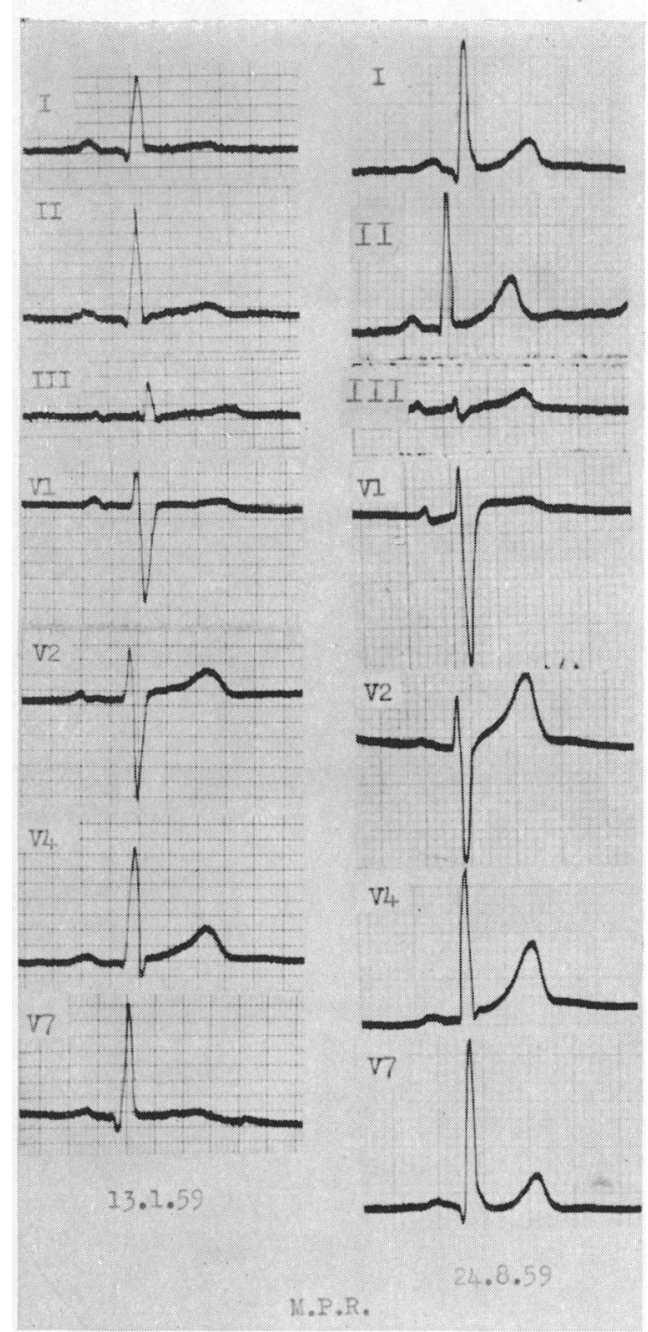

FIG. 2.-Electrocardiogram from Case 11 three weeks after onset of symptoms and seven months later. No pericardial friction was ever heard in this case.

Signs of shock, pallor, and low blood pressure occurred in two of the present series (Cases 12 and 13) and led to a confident diagnosis of cardiac infarction and the institution of anti-coagulant therapy, fortunately without ill effect. Severe shock appeared in the case reported by Coffen and Scharf (1946), in the fatal case of Pomerance et al. (1952), and mildly in 2 of the 50 cases reported by Carmichael et al. (1951). One of Davies's (1952) patients showed severe collapse in the early stages of the illness.

Pain in the chest is not always a presenting symptom and a few painless cases have been reported by Davies (1952) and Scherl (1956). Krook (1954) reports that 4 of his 24 patients had abdominal pain as the presenting symptom and that it was severe in two. In the fatal case of Pomerance et al. (1952) there was tenderness and spasm over the upper right abdominal quadrant, but this might have been of hepatic origin. Powers et al. (1955) in reporting 13 cases of ANSP state that 5 


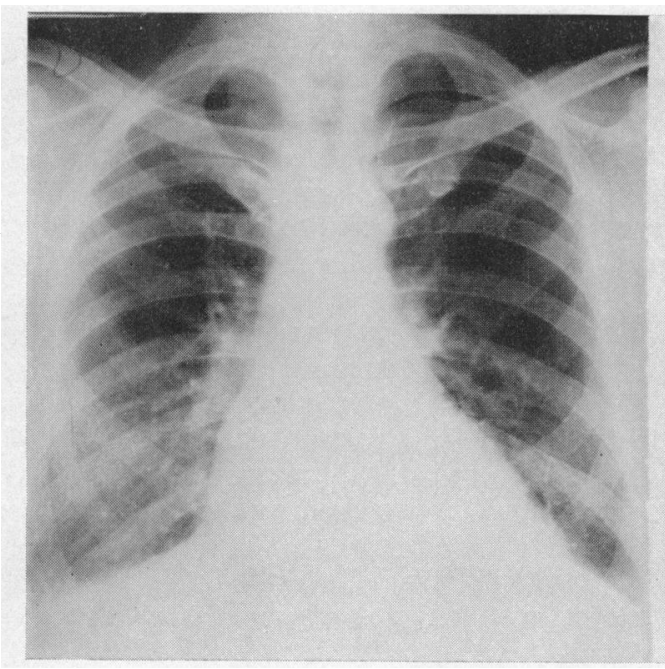

23.4.59

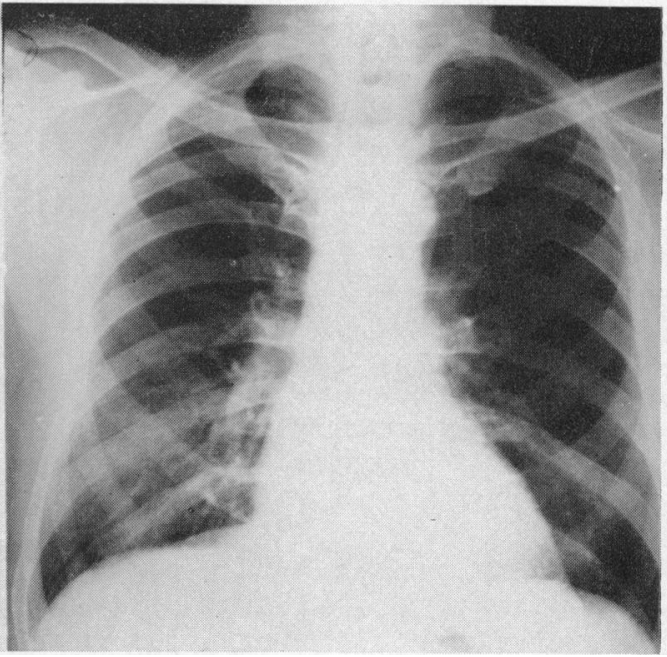

4.5.59

Fig. 3.-Chest films from Case 12 about ten days after onset of second attack, showing widened heart shadow with pleural effusion, followed by return to normal eleven days later.

complained of significant abdominal symptoms. One had a negative laparotomy and another was saved from a similar intervention by the migration of the pain into the chest. Severe abdominal pain occurred in 2 out of the 30 cases of Scherl (1956). In the fatal case in the present series (Case 14) acute upper abdominal pain occurred after ANSP was well established: it probably marked an exacerbation of pleural inflammation and led to the decision to perform laparotomy and to his death during the induction of anaesthesia. The only abnormality found in the peritoneal cavity at necropsy was enlargement of the omental and retro-peritoneal lymph nodes.

Only two fatal cases have been described before the present series which unhappily adds a third. McCord and Taguchi (1951) describe a male patient who was given anti-coagulant treatment as a case of cardiac infarction, where death occurred suddenly on the sixteenth day of illness and was due to hæmopericardium: there was intense fibrinous pericarditis and no cardiac infarction. In the case of Pomerance et al. (1952) death occurred shortly after admission in a shocked and dyspnœic woman with both abdominal and chest pain in whom surgical intervention had been seriously considered: there was pericardial tamponade with sero-sanguineous fluid. Case 14 of the present series has been mentioned above and is described in detail below. In all these cases histological examination has shown a fibrinous pericarditis with infiltration by polymorphs and lymphocytes and only slight invasion of the underlying myocardium. There has been nothing to indicate tuberculous or rheumatic inflammation.

\section{CASE REPORTS}

Case 1. Civil servant, aged 43 when first seen in 1948. He began to have attacks of severe pain behind the sternum and in the right arm in 1943. The attacks occurred at night and would last about four hours. He would go a grey colour and vomit. After an attack he would feel exhausted but be able to go to work. There were six attacks at wide intervals up to 1948. In 1946, during an attack, both he and his wife heard a scraping noise in the chest.

In June 1948 an attack developed and he sent for his doctor for the first time. Pericardial friction was present and I was sent for. The patient looked well, the temperature was normal and the blood pressure was 135/95. Loud pericardial friction was heard all over the præcordium, and was uninfluenced by respiration. An electrocardiogram showed moderate S-T elevation in leads II and CR2, 4, and 7. Next day he came to hospital. The friction rub was still present though faint, the lungs and heart were normal radiologically, 
and the cardiogram showed increased S-T elevation. The Wassermann reaction was negative. He was seen again a month later when he was quite well and the heart was normal on clinical, radiological, and electrocardiographic examination.

He then left the district but has been followed up. There have been attacks of pain once or twice a year, seventeen in all so far. In 1952 his family doctor heard pericardial friction during an attack, and the patient states that his wife has often heard a grating sound during an attack and that he himself can feel it. He remains otherwise very well. When last seen, in September 1959, he appeared to be in perfect health. The blood pressure was 130/80 and the heart was normal on clinical, radiological, and electrocardiographic examination.

Case 5. Bus conductor, aged 23. Admitted March 28, 1953. Eighteen months previously he had an attack of sharp pain behind the sternum, made worse by breathing, which lasted for one day. Ten days before admission a dull pain developed in the front of the chest which gradually became severe and he could only bear it if he kept quite still. His general condition was good. Temperature $100^{\circ} \mathrm{F}$., pulse 104, B.P. 130/80. No abnormality on clinical examination. Chest film normal. Electrocardiogram showed marked S-T elevation in I, II, CR1, 2, 4, and 7. The symptoms and fever abated in a few days and he was discharged.

Re-admitted September 13, 1953, with further chest pain, pyrexia, and fresh S-T elevation. No pericardial friction was heard. The chest film showed an opacity in the right costophrenic angle and the heart shadow was wider than before. Recovery occurred in a few days.

Re-admitted July 22, 1954, the day after the onset of deep-seated chest pain, made worse by breathing and movement, and spreading into the throat and jaws. Temperature $100^{\circ} \mathrm{F}$. No friction heard. Marked fresh S-T elevation in the electrocardiogram. The chest film showed a slightly widened heart shadow and pleural reaction in the left costophrenic angle. The attack subsided in a few days.

Re-admitted August 29, 1954. A sore throat five days previously was followed by severe pain in the chest as before. Temperature $101^{\circ} \mathrm{F}$. No pericardial friction was present on admission but on September 10 a rub was heard which persisted for nine days. The heart shadow was widened and there was again fresh S-T elevation in the electrocardiogram.

Re-admitted October 2, 1954, with another attack of chest pain and pyrexia. No friction was heard but fresh S-T elevation was again present.

Re-admitted November 12, 1954, with another attack of chest pain and pyrexia but no fresh electrocardiographic changes.

Re-admitted December 26, 1954 with persistent chest pain for the past fortnight. Afebrile and no friction heard but there was fresh slight $\mathrm{S}-\mathrm{T}$ elevation. Six days later the temperature rose, there was right pleural pain and clinical and radiological evidence of consolidation of the lower lobe of the right lung. The heart shadow was slightly widened.

During 1955 he remained well. The electrocardiogram became nearly normal but there was persistent slight S-T elevation and a low T wave in lead II. In June 1956 he had substernal pain for ten days but was not seen. In January 1958 he stated that he had had five attacks of chest pain each lasting about ten days in the past six months. The heart was normal on clinical, radiological, and electrocardiographic examination.

He was given steroid therapy during October and November 1954 and then kept on sodium salicylate 120 grains daily during 1955 and 1956 . At no time were there any joint pains or swellings. The E.S.R. was moderately raised in the initial stages of the attacks. The leucocyte count was moderately raised with polymorphs predominating.

Case 11. Labourer, aged 46. In December 1958 he had severe substernal pain going into the left arm and the left side of the neck for twelve hours. The pain returned a week later and lasted for two hours. A fortnight after this, similar severe pain developed which went on for twenty-four hours, and he was admitted in January 1959. The blood pressure was 105/70. The jugular veins showed one inch of filling, the liver was enlarged two finger-breadths, and there was a lumbar pad of œdema. There was no pericardial friction. There was a slight systolic murmur, otherwise the heart sounds were normal. A chest film showed slight widening of the heart shadow. The cardiogram showed slight S-T elevation in I, II, and V7 with low T waves (Fig. 2). The temperature was normal on admission but after seven days it rose to $100^{\circ} \mathrm{F}$. for two days. At the same time there was further central chest pain. The E.S.R. was $16 \mathrm{~mm}$. in 1 hour on admission. Serum transaminase levels were normal. The Wassermann reaction was negative. The slight heart failure disappeared. Later, cardiograms showed inversion of T in I, II, and V2, 4, and 7. After discharge he had another attack of pain and tightness in the chest made worse by breathing and was re-admitted on March 22, 1959. No pericardial friction was heard during the second admission but the electrocardiogram again 
showed slight S-T elevation in V7. After discharge he had occasional pain in the chest on deep breathing or stooping. When last seen in August 1959 he was well. The blood pressure was 140/80. The soft systolic murmur remained, but otherwise the heart was normal on clinical, radiological, and cardiographic examination (Fig. 2).

Case 12. Retired Captain, R.N., aged 58. He was admitted to another hospital on February 18, 1959, following a day of severe pain across the centre of the chest which caught his breath and made him sit up in bed. He became very short of breath. His pulse was 96 and the blood pressure was $145 / 110$ but two hours later he was cold and sweating and the blood pressure was 70/?. A levophed drip was set up and the blood pressure rose to $110 / 80$ on the following day. Thereafter it remained around 150/90. No pericardial friction was heard at any time. The serum transaminase levels were not raised. The electrocardiogram showed slight elevation of the S-T period in I, II and V2 and V6. The T wave in V6 was flat. He was regarded as a case of cardiac infarction and given anti-coagulant treatment for three weeks. After discharge he felt well for three weeks and then had further pain in the centre of the chest which made him sit up. This persisted for five days intermittently and he was admitted on April 22. He was apyrexial and the blood pressure was $110 / 80$. There was no clinical evidence of heart failure. Pericardial friction was present and persisted for two days. The E.S.R. was $82 \mathrm{~mm}$. in 1 hour. Chest films showed a widened heart shadow and small bilateral pleural effusions. Eleven days later these had been absorbed and the heart shadow was normal (Fig. 3). The electrocardiogram showed slight S-T elevation with later shallow inversion of T in I, II, and the left præcordial leads. He was discharged after 18 days, apparently well, but four days later he was re-admitted, having had another attack of retrosternal pain for the past 24 hours. The temperature was $99 \cdot 2^{\circ} \mathrm{F}$. Pericardial friction was again heard. A chest film showed some widening of the heart shadow and a small amount of fluid at the right lung base. The electrocardiogram showed some S-T elevation in V1-7 with later lowering of T. Pyrexia in this attack lasted for four days. The Wassermann reaction was negative. Three specimens of fæces gave negative cultures for HeLa cells and two specimens of serum gave negative monkey kidney tissue culture neutralization tests with the five types of Coxsackie virus, sub-group B. He took his own discharge after six days and has reported by letter. Three months after discharge he stated that he was very well and had had no further chest pain.

Case 14 (Fatal). Soldier, aged 19. On July 21, 1959, he was admitted elsewhere with a sore throat. The pharynx was injected and the temperature was $101^{\circ} \mathrm{F}$. A throat swab gave a growth of streptococcus viridans. Penicillin and aureomycin were given but the temperature did not settle. On July 27 a chest film showed a normal heart shadow and normal lung fields. Next day he complained of pain in the chest on swallowing and pericardial friction was heard. On this day a monilial stomatitis developed and antibiotics were stopped. Anticoagulant treatment was given for six days from July 30 as it was thought that pulmonary embolism might have occurred. Chest films now showed widening of the heart shadow and bilateral small pleural effusions. The electrocardiogram showed S-T elevation in most leads. There was a leucocytosis up to 22,000 per cu.mm. with polymorphs around 80 per cent. On August 7 he was in great respiratory distress with distended jugular veins, enlargement of the liver, and a small ascites. There was very loud and widespread pericardial friction. Aspiration of the pericardium was performed and bloodstained fluid was found. Only $12 \mathrm{ml}$. could be withdrawn but the patient's relief was striking. Next day he was transferred to Newcastle General Hospital. It was decided to treat him as a case of tuberculous pericarditis while awaiting the report on the pericardial fluid. He was given streptomycin $1 \mathrm{~g}$., isoniazid $600 \mathrm{mg}$., and prednisone $80 \mathrm{mg}$. daily. General improvement was marked though the pyrexia did not subside completely. The pericardial friction became fainter and 14 days after its onset it could no longer be heard. The heart shadow remained very wide and fluid persisted at both lung bases. On August 15 he complained of sudden severe epigastric pain after a large breakfast. There was much upper abdominal tenderness and rigidity, especially over the upper right quadrant. Surgical advice was sought. Although no gas could be seen under the diaphragm on X-ray it was considered that there had been a perforation of a peptic ulcer which had been sealed off, and it was thought wise to taper off the prednisone and to institute gastric suction. Slight improvement followed. There was considerable lessening of the pain which tended to shift upwards into the chest but the fever increased and the temperature started to swing, reaching $103{ }^{\circ} \mathrm{F}$. on August 25 . On this day a leucocyte count showed 50,000 per cu.mm. with 88 per cent polymorphs. There was some increase in the extent of the dullness at the right lung base and exploration yielded turbid fluid with scanty cells. Surgical advice was again sought. It was felt that the combination of a high swinging temperature, fresh right pleural effusion, and high leucocyte count following the probable perforation of a peptic ulcer were so strongly suggestive of a subdiaphragmatic abscess that exploration was justified. The heart stopped during the induction of anæsthesia. The pericardium was immediately 
opened and a large amount of blood-stained fluid escaped. Cardiac massage and defibrillatory shocks failed to restore cardiac action.

Necropsy. Both pleural cavities contained some fluid which was blood-stained on the right side. There were œdematous organizing adhesions over the lower parts of both lungs. The lungs showed mild bronchitis and collapse of the lower lobes. The hilar nodes were enlarged, pale, and fleshy. The pericardium still contained some heavily blood-stained fluid. Both layers were covered by a shaggy hæmorrhagic fibrinous exudate with friable adhesions producing a number of small loculi. The heart weighed $445 \mathrm{~g}$. The exudate over the epicardium was thickest over the left ventricle where it was up to $0 \cdot 2 \mathrm{~cm}$. thick. All the valves and great vessels appeared normal. The myocardium was pale and soft. The coronary arteries appeared normal. In the abdominal cavity there was congestion of the abdominal surface of the diaphragm on both sides. There was no local or general peritonitis. The omental and retro-peritoneal lymph nodes were enlarged. There were multiple petechial hæmorrhages in the stomach but no ulceration there or in the duodenum. The liver showed venous congestion. The spleen weighed $570 \mathrm{~g}$. and was soft, pinkish grey in colour and with prominent Malpighian bodies. There were no other significant naked-eye findings.

Histological examination. Heart. Numerous blocks from both ventricles showed an organizing fibrinous pericarditis. There was moderate cellular reaction in the base consisting mainly of macrophages, plasma cells, and lymphocytes, with small numbers of polymorphs. In several blocks from the left ventricle small foci of myocardial fibrosis were seen, usually attended by only a very slight cellular reaction (Fig. 4). Serial sections from the blocks of the first part of the anterior descending branch of the left coronary artery showed great narrowing with almost complete occlusion by atheromatous change and early thrombus formation. These changes extended over a distance of less than $1 \mathrm{~mm}$. but were severe and suggested that there had been organization of a thrombus of some duration, probably months. They had not been seen

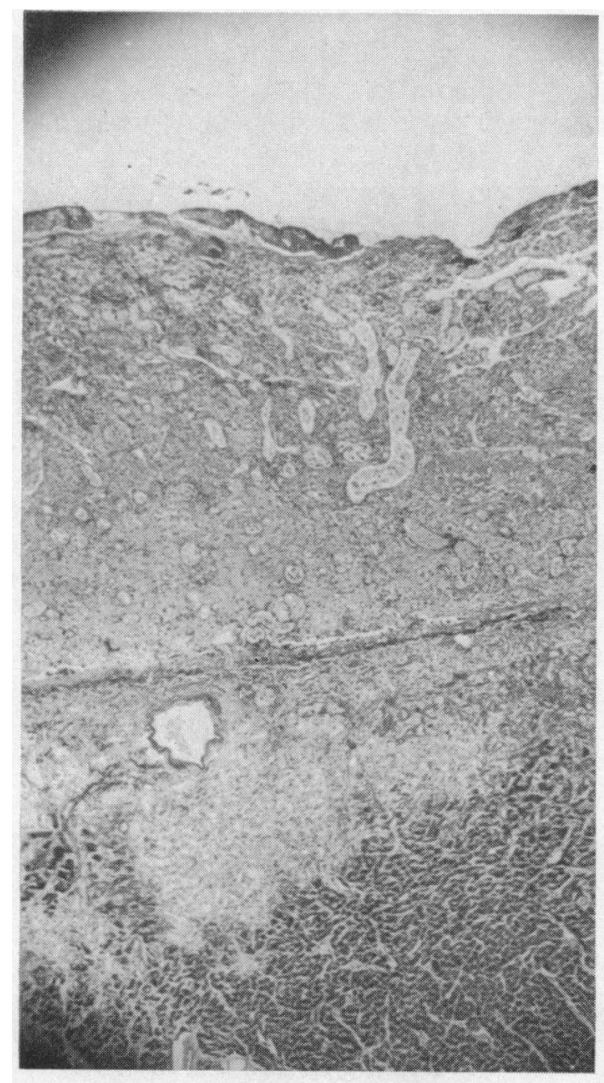

FIG. 4.-Pericardial exudate and myocardium from Case 14. 
when the artery was examined naked-eye by the usual method of serial transverse section. No other evidence of coronary artery disease was seen in the other blocks. The valves showed no abnormalities and no Aschoff nodes were seen in any section. Lungs. There was a thick layer of organizing fibrinous pleurisy, rather more cellular and vascular than the pericardial exudate. The underlying lung was congested and odematous and in the sub-pleural layer the alveoli were filled with macrophages. There was no consolidation and no vascular changes were seen. The liver was within normal limits. In the spleen there was congestion and odema of the pulp. All lymph nodes showed much non-specific reactive hyperplasia, and plasma cells were often very prominent. These changes were greatest in the thoracic nodes. The other organs showed no important changes. There was no evidence in any of the tissues of collagen vascular disease or other form of vasculitis.

Virus investigations. No virus was recovered from extracts of pericardium, heart, and blood.

Comment. Death in this case was precipitated by the induction of anæsthesia for unnecessary surgical intervention. The findings at autopsy suggest that recovery might well have taken place, probably with an adherent pericardium. No evidence of rheumatic or tuberculous inflammation was found. The coronary occlusion produced no myocardial infarction and cannot reasonably be considered to have caused the intense pericarditis and pleurisy.

TABLE

Clinical Features of 14 Patients with Acute Non-Specific Pericarditis

\begin{tabular}{|c|c|c|c|c|c|c|c|c|c|}
\hline \multirow[t]{2}{*}{ Case } & \multirow[t]{2}{*}{ Age } & \multirow{2}{*}{$\begin{array}{l}\text { Resp. } \\
\text { infection }\end{array}$} & \multicolumn{3}{|c|}{ No. of attacks } & \multirow[t]{2}{*}{ Pain } & \multirow[t]{2}{*}{ Friction } & \multirow[t]{2}{*}{ Shock } & \multirow[t]{2}{*}{ Evidence of effusion } \\
\hline & & & Hist. & Obs. & Total & & & & \\
\hline 1. & 43 & - & 15 & 2 & 17 & Severe RS and & Present & 0 & None, N.H.Sh. \\
\hline 2. & 45 & - & 0 & 1 & 1 & $\begin{array}{l}\text { Severe RS } \\
\text { on breathing and } \\
\text { coughing }\end{array}$ & On 1 day & 0 & None, N.H.Sh. \\
\hline 3. & 24 & - & 1 & 2 & 3 & $\begin{array}{l}\text { RS on moving and } \\
\text { breathing }\end{array}$ & $\begin{array}{l}\text { In 3rd attack } \\
\text { only }\end{array}$ & $\mathbf{0}$ & $\begin{array}{l}\text { Wide H.Sh. } \\
\text { Paracentesis }\end{array}$ \\
\hline $\begin{array}{l}4 . \\
5 .\end{array}$ & $\begin{array}{l}25 \\
23\end{array}$ & Cough & $\begin{array}{l}1 \\
2\end{array}$ & $\begin{array}{l}1 \\
6\end{array}$ & $\begin{array}{l}2 \\
8\end{array}$ & $\begin{array}{l}\text { RS } \\
\text { Severe RS. } \\
\text { on breathing }\end{array}$ & $\begin{array}{l}\text { For } 10 \text { days } \\
\text { In } 1 \text { attack } \\
\text { only }\end{array}$ & $\begin{array}{l}\mathbf{0} \\
\mathbf{0}\end{array}$ & $\begin{array}{l}\text { Wide H.Sh. } \\
\text { Wide H.Sh. }\end{array}$ \\
\hline 6. & 35 & $\begin{array}{l}\text { Sore throat. } \\
\text { Consoli- } \\
\text { dated R. } \\
\text { lower lobe }\end{array}$ & 0 & 1 & 1 & $\begin{array}{l}\text { Severe RS. } \\
\text { on breathing }\end{array}$ & For 3 days & 0 & None, N.H.Sh. \\
\hline 7. & 75 & Bronchitis. & 0 & 1 & 1 & RS & Present & 0 & Sl., wide H.Sh. \\
\hline 8. & 66 & $\begin{array}{l}\text { Opacity R. } \\
\text { lung base }\end{array}$ & 0 & 2 & 2 & $\begin{array}{l}\text { Severe RS. } \\
\text { on breathing }\end{array}$ & For 3 days & & None, N.H.Sh. \\
\hline 9. & 45 & - & 0 & 1 & 1 & $\begin{array}{l}\text { RS on breathing } \\
\text { and coughing }\end{array}$ & Not heard & $\mathbf{0}$ & None, N.H.Sh. \\
\hline 10. & 28 & 一 & 0 & 1 & 1 & $\begin{array}{l}\text { RS on movement } \\
\text { and breathing }\end{array}$ & Not heard & 0 & None, N.H.Sh. \\
\hline 11. & 46 & $\begin{array}{l}\text { Chronic } \\
\text { cough }\end{array}$ & 3 & 2 & 5 & $\begin{array}{l}\text { Severe RS and } \\
\text { left arm on } \\
\text { breathing }\end{array}$ & Not heard & 0 & Sl., wide H.Sh. \\
\hline 12. & 58 & - & 0 & 3 & 3 & $\begin{array}{l}\text { Severe RS on } \\
\text { breathing }\end{array}$ & $\begin{array}{l}\text { In 2nd \& 3rd } \\
\text { attacks }\end{array}$ & $\begin{array}{l}+ \text { in } 1 \text { st } \\
\text { attack. } \\
\text { B.P. 70/? }\end{array}$ & $\begin{array}{l}\text { Wide H.Sh. Small } \\
\text { pleural effusions }\end{array}$ \\
\hline 13. & 54 & 一 & 0 & 1 & 1 & Severe RS & For 1 month & $\begin{array}{l}\text { Moderate. } \\
\text { B P } 90 / 55\end{array}$ & Sl., wide H.Sh. \\
\hline $14 . \dagger$ & 19 & Sore throat & $\mathbf{0}$ & 1 & 1 & $\begin{array}{l}\text { Central chest on } \\
\text { swallowing. } \\
\text { Later severe } \\
\text { abdominal }\end{array}$ & For 14 days & D.r. 90/J0 & $\begin{array}{l}\text { Large Pc. effusion. } \\
\text { Paracentesis. } \\
\text { Bilateral pleural } \\
\text { effusions }\end{array}$ \\
\hline
\end{tabular}

RS, Retrosternal. N.H.Sh., Normal heart shadow. Pc., Pericardial. † Died

\section{Aetiology}

The cause of acute non-specific pericarditis is unknown in most reported cases. A virus infection probably accounts for some. Fletcher and Brennan (1957) describe pericarditis in a young woman 
whose serum gave a positive neutralization test for Coxsackie virus, sub-group B 4: the patient's mother and father were both ill at the same time with a febrile illness and the mother had pericardial friction. Pericarditis has also been described in Reiter's syndrome by Csonka and Oates (1957).

It is hard, however, to accept a virus infection as the explanation of repeated attacks of pericarditis for many years and it is probable that ANSP has more than one cause.

Dressler (1959) has described 44 patients with a relapsing type of benign pericarditis after cardiac infarction, which closely resembles ANSP except for the evidence of cardiac infarction. He postulates a sensitization by necrotic muscle tissue and supports this view by the beneficial effect of steroid therapy. That some such mechanism may follow direct injury to the heart from gunshot wounds has been shown by Wood (1957) who described five cases of recurrent pericarditis with effusion following the lodging of a metallic foreign body in or near the heart: the attacks developed during convalescence and were benign. The benign pericarditis that may occur at an interval after operations on the heart seems probably to have the same ætiology.

No ætiological agent could be found in our patients but virus studies were only made in the last three. In Cases 12 and 13, the serum gave negative monkey kidney tissue culture neutralization tests with the five types of Coxsackie virus sub-group B and the fæces produced no cytopathogenic agent on HeLa and monkey kidney cell culture. In Case 14, HeLa, amnion, and monkey kidney cell culture yielded no cytopathogenic agent from myocardium and pericardium removed at autopsy. It may be significant that two patients (Cases 7 and 8) lived in adjacent streets and became ill within a month of each other but there was no known contact between them. Evidence of respiratory infection was present in 8 patients of whom 2 had sore throats, 3 complained of cough, and 3 had radiological evidence of pneumonic consolidation.

\section{Discussion}

Acute non-specific pericarditis is probably due to more than one cause. That it can be a virus infection seems to be established (Fletcher and Brennan, 1957) but its occurrence after wounds of the heart, operations on the heart, and cardiac infarction suggests that an auto-immune reaction may be responsible under these circumstances. It is probably commoner than the number of cases reported in Britain would suggest. A number of cases are probably wrongly diagnosed as cardiac infarction and in these the giving of anti-coagulant treatment may be dangerous (McCord and Taguchi, 1951).

Although the illness is usually benign it can run a long course with frequent relapses, and occasionally pericardial tamponade can produce severe distress or death (Case 3 of Pomerance et al., 1952, and Case 14 of this series). Constrictive pericarditis following ANSP has been recorded as a late complication (Krook, 1954) and may account for some of the non-tuberculous constrictions found at operation.

The diagnosis of ANSP is usually not difficult if careful attention is given to the electrocardiogram. Abdominal pain may be a misleading symptom and it is suggested that routine electrocardiography of all doubtful abdominal emergencies might be valuable.

Treatment until recently has been mainly expectant but there seem to be good reasons for giving steroid therapy to severe cases (Dressler, 1959).

\section{SUMMARY}

Fourteen patients with acute non-specific pericarditis are presented. All were men and their ages ranged from 19 to 75 years.

Pericardial friction was not heard in three patients.

Six patients had more than one attack and one had 17 attacks in 16 years.

Shock was present in two patients. Severe abdominal pain simulating perforation of a peptic ulcer occurred in one patient and led to his death during the induction of anæsthesia for laparotomy.

No ætiological agent was found in any of the cases. 
My thanks are due to Professor G. A. Smart and to Dr. C. N. Armstrong, C. B. Henderson, G. O. Richardson, and P. Szekely for permission to publish cases under their care, to Dr. J. H. Hale of the Public Health Laboratory Service for the virological studies, and to Dr. T. Bird for the report of the autopsy on Case 14.

\section{REFERENCES}

Barnes, A. R., and Burchell, H. B. (1942). Amer. Heart J., 23, 247.

Bower, B. D., Gerrard, J., and MacGregor, M. E. (1953). 'Brit. med. J., 1, 244.

Carmichael, D. B., Sprague, H. B., Wyman, S. M., and Bland, E. F. (1951). Circulation, 3, 321.

Chapman, D. W., and Overholt, E. (1957). Arch. intern. Med., 99, 708.

Coffen, and Scarf, M. (1946). Amer. Heart J., 32, 515.

Csonka, G. W., and Oates, J. K. (1957). Brit. Med. J., 1, 866.

Davies, D. H. (1952). Brit. Heart J., 14, 309.

Dressler, W. (1959). Arch. intern. med., 103, 28.

Fletcher, E., and Brennan, C. F. (1957). Lancet, 1, 913.

Katz, M., and Jackson, A. (1957). Amer. Practiti. tr., 8, 936.

Krook, H. (1954). Acta med. Scand., 148, 201.

McCord, M. C., and Taguchi, J. T. (1951). Arch. intern. Med., 87, 727.

Pomerance, M., Perchuk, E., and Hoffman, J. B. (1952). New York State J. Med., $52,95$.

Powers, P. P., Read, J. L., and Porter, R. R. (1955). J. Amer. med. Ass., 157, 224.

Scherl, N. D. (1956). J. Mount Sinai Hosp., 23, 293.

Tomlin, C. E., Logue, R. B., and Hurst, J. W. (1952). J. Amer. med. Ass., 149, 1215.

Will, G., and Fleming, J. (1958). Scot. med. J., 3, 484.

Wood, P. (1957). Diseases of the Heart and Circulation. London. 